\title{
IMPROVING SUSTAINABLE DEVELOPMENT THROUGH SUPPLY CHAIN INTEGRATION: AN EVIDENCE FROM JORDANIAN PHOSPHATE FERTILIZERS MANUFACTURING COMPANIES
}

\author{
Abdel-Aziz A. Sharabati ${ }^{1}$, Nidal A. Al-Salhi ${ }^{2}$, Omar M. Bwaliez ${ }^{3, *}$, Mahmoud N. Nazzal ${ }^{1}$ \\ ${ }^{1}$ Business Administration Department, Faculty of Business, Middle East University, Amman, Jordan \\ ${ }^{2}$ Business Administration Department, Faculty of Administrative and Financial Sciences, University of Petra, Amman, Jordan \\ ${ }^{3}$ Management Sciences Department, School of Management and Logistics Sciences, German Jordanian University, Amman, Jordan
}

\begin{abstract}
The study aims to investigate the effect of supply chain integration (SCI) in terms of supplier integration (SI), internal integration (II), and customer integration (CI) on sustainable development (SD) of Jordanian phosphate fertilizers manufacturing (JPFM) companies in terms of economic responsibility (ECR), social responsibility (SOR), and environmental responsibility (ENR). The study model and hypotheses were developed based on the literature review. The data were collected from 102 managers through a structured questionnaire. Normality, validity, and reliability of the questionnaire items were confirmed. Then, descriptive statistical analysis, the correlation between variables, and multiple linear regression were carried out. The results revealed that the overall SCI has a positive and significant effect on the overall SD. The results also provided evidence that SI, II, and CI have a positive and significant effect in enhancing SD. However, II is superior to external integration (SI and CI) in enhancing SD. This study promotes the idea of implementing SCI in JPFM companies in order to enhance their SD. It also recommends these companies rethink their efforts toward economic, social, and environmental responsibilities. This study is one of the first studies that create awareness about adopting SD by Jordanian companies, especially that SD still does not have the highest priority in Jordan. In addition, it is the first study in Jordan that is conducted in the phosphate fertilizers manufacturing sector.
\end{abstract}

Keywords

Supply chain integration, Sustainability, Supplier integration, Internal integration, Customer integration, Jordanian Phosphate fertilizers.

\section{Introduction}

Today, it is largely acknowledged that sustainable development (SD) has to be considered in the supply chain's corporate strategy development (Brömer et al., 2019). It is well known that SD promotes economic prosperity, increased social welfare, and environmental protection (Sharabati, 2018). Adopting SD by a company can influence its financial performance (Agyemang and Ansong, 2017), reputation (Fatma et al., 2015; Agyemang and Ansong, 2017), and innovation (Shin et al., 2018). It is crucial for companies to strive for SD because it provides the best ways to improve the lives of people everywhere. However, many companies still face challenges to achieve SD (Abbasi and Nilsson, 2012), especially when expanding their efforts toward their suppliers and customers (Brömer et al., 2019).

The concept of supply chain integration (SCI) was developed in order to overcome these challenges and enhance the supply chain management (SCM) of companies (Lii and Kuo, 2016). However, efficient and effective SCM requires integration of processes not only internally within an organization but also externally across suppliers and customers (Chang et al., 2016). SCI can be defined as a coordinated collaboration between the company and its partners of suppliers and customers comprising effective management of materials, services, information, money, and decisions (Flynn et al., 2010; Chang et al., 2016; Lii and Kuo, 2016; Ayoub et al., 2017; Kang et al., 2018). Several scholars agreed on classifying SCI into three common dimensions: supplier integration (SI), internal integration (II), and customer integration (CI) (Mackelprang et al., 2014; Ayoub et al., 2017; Kang et al., 2018). These dimensions represent upstream, internal, and downstream operations respectively (Ayoub et al., 2017). SI and CI are forms of external integration and refer to the coordination and cooperation of information, processes, and behaviors of a company with its suppliers and customers (Chang et al., 2016; Kang et al., 2018).

*Corresponding author: Omar M. Bwaliez, E-mail: omar.bwaliez@gju.edu.jo 
While, II refers to the coordination and cooperation of information, processes, and behaviors between functions within a company (Flynn et al., 2010; Chang et al., 2016; Kang et al., 2018).

SCI has recently turned into a predominant research topic (Stevens and Johnson, 2016). Today, a wide stream of scholarly works focuses on the influence of SCI on many outputs, such as organizational performance (Flynn et al., 2010; Mackelprang et al., 2014; Ralston et al., 2015; Chang et al., 2016), and competitiveness (Lii and Kuo, 2016), and innovation (Boon-itt, 2009; Ayoub et al., 2017). However, the literature still lacks enough understanding of whether and to what extent the SCI influence SD.

Jordan is one of five countries that control about $90 \%$ of the world's known reserves of phosphate (Titi et al., 2019). Most of the phosphate in Jordan is used in the fertilizer industry, where phosphate fertilizers are considered better than other fertilizers for plant nutrition. Due to its high economic relevance and its exposure to increasing sustainability requirements, the phosphate fertilizers manufacturing industry in Jordan was chosen as the empirical research field. There are many previous studies that have addressed the extent to which the SD dimensions are applied in various Jordanian sectors, such as the pharmaceutical industry (Sharabati, 2018), banking (Di Bella and Al-Fayoumi, 2016; Masa'deh et al., 2018), mobile telecommunications (Obeidat, 2016), and hotel industry (Al Qeed, 2015). However, Jordanian academics and practitioners still have no enough insight if the phosphate fertilizers industry is moving toward SD or not, and how to improve the SD of its supply chain.

In light of the justifications mentioned above, the study at hand is dedicated to investigate the effect of SCI on SD of the JPFM companies via answering the following research questions:

$R Q 1$. How does SCI influence SD?

$R Q 2$. How do the three dimensions of SCI influence SD?

By answering these important questions, this research paper extends sustainability research into supply chains and provides the following theoretical contributions. First, it provides new perspectives from which to understand the important role of SCI in improving SD. Second, it provides practical insights into the ways manufacturers can successfully implement SCI to achieve their desired SD. On the other hand, this research paper provides the following practical contributions. First, it is one of the first studies that create awareness about adopting SD by Jordanian companies, especially that SD still does not have the highest priority in Jordan. Second, to the best of the authors' knowledge, no empirical studies have been conducted in Jordan, especially in the phosphate fertilizers manufacturing sector, to investigate the SCI-SD link.

\section{Literature review}

We examined the literature related to SCI, SD, and their dimensions to develop the theoretical background for this study.

\subsection{SCI}

Companies' strategic efforts to improve the efficiency and effectiveness of supply chain activities and processes depend heavily on SCI (Chang et al., 2016). SCI is the effective coordination and cooperation of supply chain processes through the seamless flow of information up and down the supply chain (Krajewski et al., 2019). That is why SCI is considered the foundation of SCM (Pagell, 2004). SCI can be defined as "the degree to which a manufacturer strategically collaborates with its supply chain partners and collaboratively manages intra- and interorganization processes. The goal is to achieve the effective and efficient flows of products and services, information, money, and decisions, to provide maximum value to the customer at low cost and high speed" (Flynn et al., 2010, p.59). Scholars classified SCI into two main categories: internal and external integration. II focuses on cross-functional activities, while external integration includes both SI and CI (Stevens and Johnson, 2016; Ayoub et al., 2017; Kang et al., 2018). These three dimensions are explained in more detail in the following subsections.

\subsubsection{SI}

SI focuses on improving the performance of the supply chain between a company and its supply base (Stevens and Johnson, 2016). Li et al. (2006) defined SI as the ability of a company to develop, manage, and maintain a 
strong and long-term relationship with its suppliers. SI involves a partnership model, with deeper, more long-term relationships, and more information sharing with fewer suppliers (Stevens and Johnson, 2016).

\subsubsection{II}

II can be defined as "the degree to which a manufacturer structures its own organizational strategies, practices, and processes into collaborative, synchronized processes, in order to fulfill its customers' requirements and efficiently interact with its suppliers" (Flynn et al., 2010, p. 59). In addition, II refers to the practices of generating knowledge sharing beyond the borders of functions and departments within the company to facilitate its external integration and attain its goals (Kim, 2013). In brief, II focuses on cross-functional collaboration within companies (Kang et al., 2018). II includes information sharing, joint decision making, and cross-functional teamwork (Flynn et al., 2010).

\subsection{3. $C I$}

$\mathrm{CI}$ can be defined as a set of practices that focus on handling customer complaints, establishing long-term relationships with customers, and improving customer satisfaction (Li et al., 2006). CI enhances information sharing between the company and its customers. The company obtains feedback from its customers then transforms it into operational information about inventory, forecasts, and schedules (Lau et al., 2010).

\section{2. $S D$}

Since the term "sustainability" first appeared in the literature over 20 years ago, numerous academics and practitioners have proposed multiple definitions of this term. The World Commission on Environment and Development (WCED) - Brundtland Commission defined sustainability as "using resources to meet the needs of the present without compromising the ability of future generations to meet their own needs" (WCED, 1987). From a corporate point of view, this definition asserts not only a focus on economic aspects of companies but also a need to focus on the sustainment of nature's resources and the societies they serve. That is why there are more than one nomenclature and synonym to the term SD, including sustainability, triple bottom line (TBL or 3BL), profit-people-planet (3Ps), and economics-environment-equity (3Es), among others (Winter and Knemeyer, 2013; Sharabati, 2018). Although different authors defined these phrases in different ways, it seems that there is a consensus among them about economic responsibility (ECR), social responsibility (SOR), and environmental responsibility (ENR), which are common dimensions of these phrases. While ECR is a traditional dimension and its measurements are well agreed-upon, SOR and ENR are new dimensions that are less prevalent and much more difficult to measure. These responsibilities are explained in more detail in the following subsections.

\subsection{1. $E C R$}

ECR addresses the economic needs of any entity that supplies the capital for producing products and services or relies on the company for wages or rewards such as shareholders, employees, customers, business partners, and financial institutions (Krajewski et al., 2019). The long-term success and competitiveness of a company are the basis of the ECR dimension (Winter and Knemeyer, 2013). In contrast to SOR and ENR dimensions, ECR is principally quantitative in nature and focused on the efficient use of resources and achieving a return on investment.

\subsubsection{SOR}

SOR addresses the moral, ethical, and charitable expectations that society gets from the company (Krajewski $e t$ al., 2019). SOR is bipolar, as it refers to both individuals and organizations (Winter and Knemeyer, 2013). Although SOR is basically based on material conditions, it is immaterial and hard to measure (Lehtonen, 2004). Hall and Matos (2010) asserted that the SOR dimension of SD is emerging as the key challenge in sustainable supply chains, due to the fact that companies have to fasten a wide range of partners with different goals, demands, and opinions that may understand the same situation differently. SOR in terms of employee health and safety systems boosts employee well-being (Pagell and Gobeli, 2009).

\subsubsection{ENR}

ENR addresses the ecological needs of the planet and the company's supervision of the natural resources used in producing products and services (Krajewski et al., 2019). ENR incorporates the set of objectives, plans, and mechanisms that promote ecological obligation and energize the development and dissemination of naturally friendly technologies (Klassen, 2001). Achieving ENR includes designing eco-friendly products (Hammouri et 
al., 2009), reusing, recycling, and remanufacturing materials, components, and returned products (Sarkis et al., 2010).

\section{Hypotheses development and research model}

In the following subsections, we discuss each construct (SCI, SI, II, CI, and SD) and develop the hypotheses on how they are related.

\subsection{SCI and SD}

Huo (2012) showed that both internal and external integration, directly and indirectly, enhance the company's performance. Pagell and Wu (2009) exemplified how SCI leads to ECR, SOR, and ENR using case studies of ten supply chains from ten different organizations. Shee et al. (2018) found that cloud-enabled SCI is positively related to supply chain performance, which eventually influenced the company's sustainability. Capitalizing on the previous discussion, it is hypothesized that:

$H_{1}$. SCI positively and significantly affects SD.

\subsection{SI and $S D$}

Effective long-term partnership with suppliers is vital for companies to make the transition to sustainability (Elkington, 1998) and overcome several sustainability challenges (Huq et al., 2016). A recent study by Bwaliez and Abushaikha (2019) revealed that lean-based SI practices can improve the company's ECR in terms of profitability, competitive position, as well as customer and employee satisfaction. Further, SI can affect SOR by creating codes of conduct that monitor the focal company and its widespread supply chain (Worthington, 2008). Baliga et al. (2019) also found that SI can lead to successful ENR practices in the supply chain. Likewise, Hajmohammad et al. (2013) stated that the focal company in the supply chain can utilize the knowledge of its suppliers for environmental innovations. All of these findings are recognized by several companies such as Starbucks, which not only attempt to pay reasonable prices to its suppliers but also make valuable contributions to enhance their social and environmental standards. Consequently, engaging in joint activities with suppliers can help a company attain sustainability issues (Yang et al., 2010), as SI is a vital enabler for both intra- and interorganizational sustainability management practices, which in turn affect the three aspects of sustainability performance positively (Kang et al., 2018). This is also confirmed by Yadav et al. (2018) who acknowledged that effective offshore outsourcing from suppliers leads to improved SD and increased cost efficiencies of the business. Neutzling et al. (2018) also asserted the crucial role of inter-organizational SI in achieving ECR, SOR, and ENR, which can be converted into improved SD. Hence, the following hypothesis is developed:

$H_{1 \mathrm{a}}$. SI positively and significantly affects SD.

\subsection{II and $S D$}

II may play a central role in enhancing SD through cross-functional information sharing and collaboration (Wolf, 2014). II promotes the alignment of functional practices and goals with a strategic business priority of SD (Narasimhan and Das, 2001). In addition, Flynn et al. (2010) found that II directly and significantly affects both operational and business performance of manufacturing companies. Further, Huo (2012) showed that II leads to improved ECR of the company. For all of these reasons, the following hypothesis is proposed:

$H_{1 \mathrm{~b}}$. II positively and significantly affects SD.

\section{4. $C I$ and $S D$}

Shee et al. (2018) found that there is a direct relationship between CI and supply chain performance. Flynn et al. (2010) showed that CI helps the company better understand customer requirements and better forecast customer demand, which in turn leads to better FR of the company. Further, companies that focus on CI can achieve greater profitability by providing quality products and services while maintaining social and environmental sustainability (Kang et al., 2018). Adopting CI practices by companies can help in information acquisition from the customers about their economic, social, and environmental needs and concerns (Gelhard and von Delft, 2016). Moreover, Neutzling et al. (2018) also asserted the crucial role of inter-organizational CI in achieving ECR, SOR, and ENR, which can be converted into improved SD. Consequently, the following hypothesis should be investigated: $H_{1 \mathrm{c}}$. CI positively and significantly affects SD. 


\subsection{Research model}

A proposed research model that combines all of the aforementioned hypotheses is shown in Figure 1. The model includes the overall SCI variable with its sub-variables, namely SI, II, and CI (i.e., independent variables), and the overall SD variable with its sub-variables, namely ECR, SOR, and ENR (i.e., dependent variables). Additionally, this model proposes that the overall SCI will have a positive relationship with the overall SD represented with $H_{1}$. Likewise, each SCI sub-variable (i.e., SI, II, and CI) will have a positive relationship with the overall SD represented by $H_{1 \mathrm{a}}, H_{1 \mathrm{~b}}$, and $H_{1 \mathrm{c}}$ respectively.

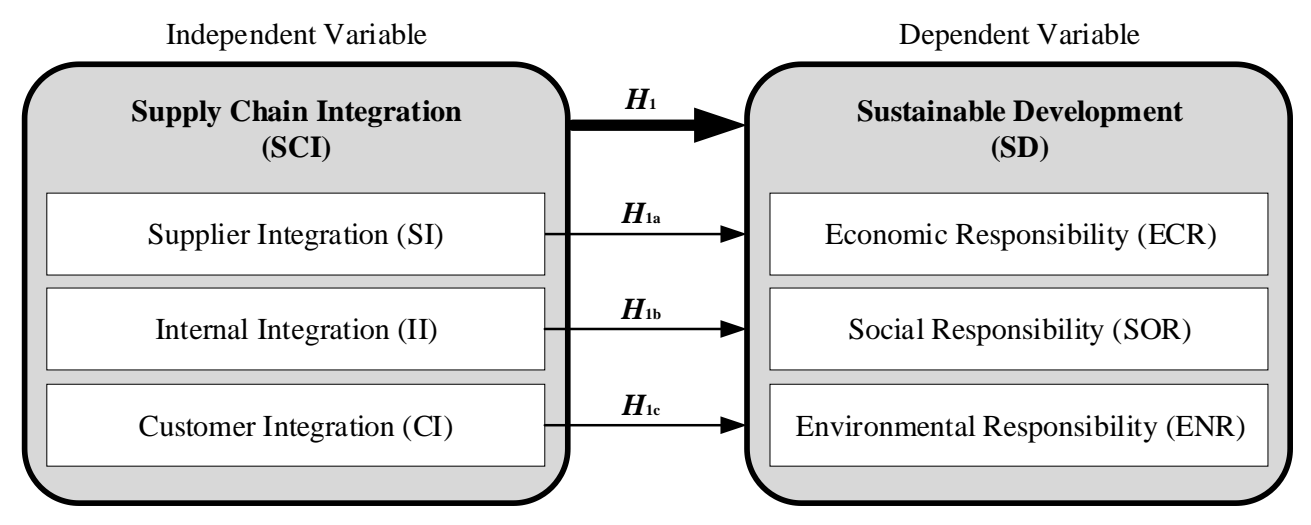

Figure 1: Research model

Sources: Kim, 2013; Kang et al., 2018; Shee et al., 2018; Baliga et al., 2019

\section{Methodology}

This research is a cross-sectional cause-and-effect study. It aims to study the effect of SCI on SD of JPFM companies. In order to achieve this objective, a research instrument was developed, data were collected, and detailed statistical analyses were carried out. These stages are presented in the following subsections.

\subsection{Research instrument}

Based on the literature review, relevant questionnaire items were drafted in order to measure the construct latent variables of the research model. To improve the understanding of its content, the resulting draft was reviewed by 15 academic professors in the field of business administration, as well as five executive managers from different JPFM companies. Then, some modifications were made according to their notes and recommendations. It is worth mentioning that the items were ensured to be written in such a way that reduces the likelihood of misunderstanding the overall SCI or SD sub-variable by the respondent. In its final form, the questionnaire comprised two main sections; the first section included questions about respondent's demographic characteristics (i.e., gender, age, academic qualification, years of experience, managerial position, and department), while the second section of the questionnaire contained 48 follow-on accurate and specific items about the implementation of each SCI and SD sub-variable. The respondents were asked to evaluate each item using a five-point Likert scale anchored from $1=$ not adopted to 5 = fully adopted and centered at 3 = partially adopted. The finished questionnaire items are shown in the Appendix.

\subsection{Research population and sample}

Three main companies dominate the phosphate fertilizers manufacturing industry in Jordan. These companies are Jordan India Fertilizers Co. (JIFCO) in Al-Shidiya, Jordan Phosphate Mines Co. (JPMC) in Aqaba, and Indo Jordan Chemicals Co. (IJC) in Amman. All of these companies were targeted to collect data, which negated the need for sampling. The questionnaire unit of analysis is each one of all the 300 managers working at the top management level, middle management level, and operational level in these three companies. To test the questionnaire items for their clarity, comprehensiveness, and acceptability, a pretest pilot study was conducted before distributing the questionnaire to the targeted companies. After finalizing the pilot study and distributing the questionnaire to all of them, a total of 135 responses were received. Only 102 responses were valid for further 
analysis, making a response rate of $75.5 \%$. This high response rate is due to distributing the questionnaire by hand (Harris et al., 1979). The authors of this study administrated and aggressively followed up the questionnaire distribution process themselves. Their involvement contributed to the delivery of the questionnaire to as many respondents as possible and helped in clarifying any ambiguity concerning the definitions or any other issues related to the questionnaire. In addition, this response rate is in line with previous empirical studies conducted in Jordan that used a similar distribution methodology (e.g., Al-Tahat and Bwaliez, 2015; Ayoub et al., 2017; Bwaliez and Abushaikha, 2019; Rifai et al., 2021; Ta'Amnha et al., 2021). Thereafter, the data from these questionnaires were coded against the statistical packages for the social sciences (SPSS) to conduct the needed analysis.

\subsection{Checking the collected data}

Several researchers (e.g., Hair et al., 2010; Sekaran and Bougie, 2010; Berenson et al., 2020) recommended that normality, linearity, multicollinearity, and independence of errors should be ensured before conducting the hypotheses testing. These four assumptions were tested as explained in the next subsections.

\subsubsection{Normality test}

In order to test the normality of response data, a histogram of residuals and one-sample Kolmogorov-Smirnov (KS) $\mathrm{Z}$ test for all variables and sub-variables were conducted. The histogram drawn in Figure 2 shows that the data are normally distributed, so the residuals do not affect the normal distribution of data. For the (K-S) $\mathrm{Z}$ test, if the significance of K-S Z is more than 0.05 then the normality of data is assumed (Bollen et al., 2005). Table 1 shows that the significance of K-S Z of all variables and sub-variables is more than 0.05 except for II, which means that the normality of the response data is not violated.

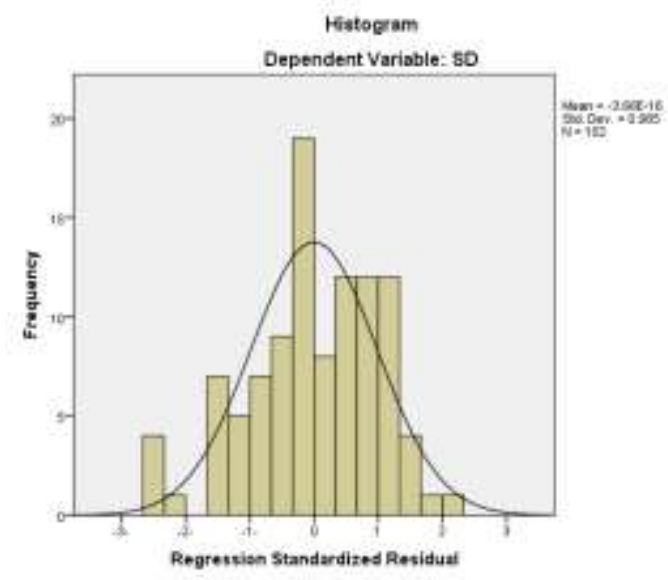

Figure 2: Normality test

Table 1: One-sample Kolmogorov-Smirnov Z test

\begin{tabular}{ccc}
\hline Sub-variable / Variable & Kolmogorov-Smirnov Z & Sig. (two-tailed) \\
\hline SI & 0.780 & 0.576 \\
II & 1.738 & 0.006 \\
CI & 1.060 & 0.211 \\
SCI & 0.880 & 0.421 \\
ECR & 1.255 & 0.086 \\
SOR & 1.337 & 0.056 \\
ENR & 0.775 & 0.586 \\
SD & 0.944 & 0.335 \\
\hline
\end{tabular}

\subsubsection{Linearity test}

To test the linearity, we depend on plotting the observed cumulative probability against the expected cumulative probability of the studied data. Figure 3 shows that the relationship between the independent and dependent variables is linear. 


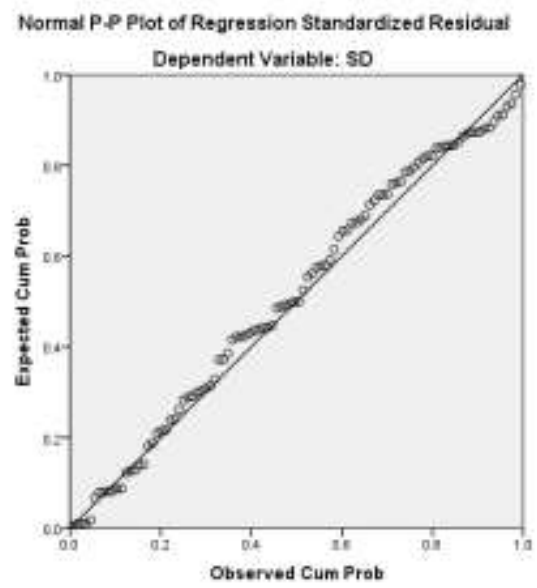

Figure 3: Linearity test

\subsubsection{Multicollinearity}

Tolerance and variance inflation factor (VIF) tests are usually used to test multicollinearity (Sharabati, 2018). If the tolerance value is more than 0.2 and the VIF value is less than 10, the data do not violate the multicollinearity assumption. Table 2 shows that the tolerance values are more than 0.2, and VIF values are less than 10. This indicates that there is no multicollinearity within the independent variables of the study.

Table 2: Multicollinearity test

\begin{tabular}{ccc}
\hline SCI sub-variable & Tolerance & VIF \\
\hline SI & 0.634 & 1.577 \\
II & 0.615 & 1.626 \\
CI & 0.680 & 1.471 \\
\hline
\end{tabular}

\subsubsection{Independence of errors}

Figure 4 shows that the errors are independent of each other. Durbin-Watson test is usually used to ensure the independence of errors (Sharabati, 2018). If the Durbin-Watson value is about 2, the data do not violate the independence of errors assumption (Alkunsol et al., 2019). For this study, the Durbin-Watson value is 1.515, which is around 2, so the residuals are not correlated with each other. This means that the independence of errors is not violated.

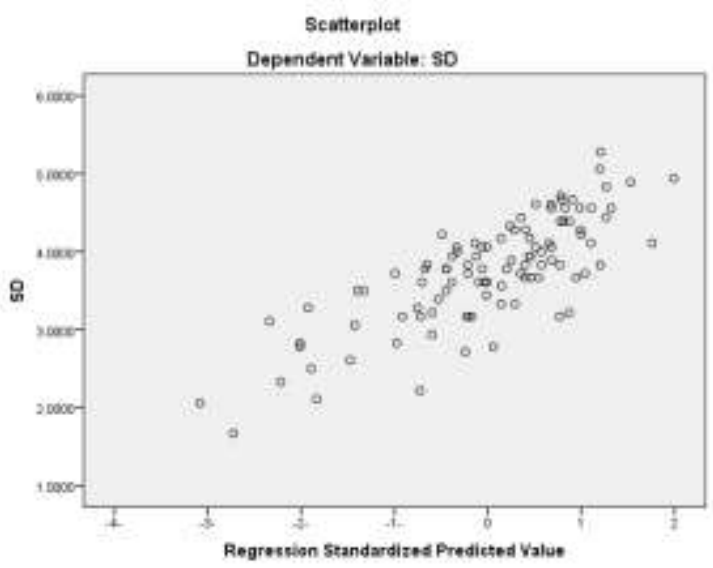

Figure 4: Scatter plot

\subsection{Instrument's validity and reliability}

The validity of the research instrument can be confirmed by ensuring content, face, and construct validity (Sharabati, 2018). To ensure the content validity of the research instrument, questionnaire items were drafted 
based on multiple sources of data (i.e., different scholarly works presented in the aforementioned literature review). To ensure face validity, the resulting draft was reviewed by 15 academic professors in the field of business administration, as well as five executive managers from different JPFM companies. Thereafter, some modifications were made according to their notes and recommendations in order to improve the understanding of the content of the questionnaire.

To ensure construct validity, principal component factor analysis, Kaiser-Meyer-Olkin (KMO) test, Bartlett's sphericity test, and percentage of explained variance were used. Factor analysis refers to the explanatory and conformity of data. Factor loading more than 0.5 is good and accepted (Hair et al., 2010, 2014). KMO value between 0.80 and 1 refers to high adequacy, and a value more than 0.60 is accepted. Bartlett's sphericity determines the suitability of data and correlation. Explained variance value shows the explanation power of the factors (Kaiser, 1974). Explained variance percentage of $40 \%$ or more is accepted (Berenson et al., 2020).

Finally, if the significance value (Sig.) of the sample is less than 0.05 at $95 \%$ confidence, the factor analysis is useful. Table 3 shows that the factor 1 value for all variables and sub-variables is ranging between 0.803 and 0.899 , which indicates that all variables and sub-variables are matching together and have strong explanatory and conformity power. Table 3 also shows that all KMO values are more than 0.6, which indicates acceptable adequacy of sampling. The significance of Bartlett's sphericity is less than 0.05 , which refers to the high suitability of data and correlation. Moreover, the percentages of explained variance are more than $40 \%$ for all variables and sub-variables, which means that the instrument has the power and capability to explain each variable and subvariable in the study.

Reliability measures the internal consistency of the construct latent variables. It is checked using the Cronbach's alpha $(\alpha)$ coefficient, a popular measure of the degree to which different questionnaire items complement each other and measure the same concept (Litwin, 1995). According to many scholars (e.g., Hair et al., 2010, 2014; Sekaran and Bougie, 2010), Cronbach's $\alpha$ value of more than 0.70 ensures good reliability of the research instrument. Table 3 shows that Cronbach's $\alpha$ values for all variables and sub-variables are accepted, where they are ranging between 0.760 and 0.898 . This indicates acceptable internal consistency of the research instrument.

Table 3: Validity and reliability tests

\begin{tabular}{|c|c|c|c|c|c|c|c|c|}
\hline \multirow{3}{*}{$\begin{array}{c}\text { Variable / Sub- } \\
\text { variable }\end{array}$} & \multicolumn{6}{|c|}{ Validity test } & \multirow{2}{*}{\multicolumn{2}{|c|}{ Reliability test }} \\
\hline & \multirow{2}{*}{$\begin{array}{c}\text { Factor } 1 \\
\text { loading } \\
\text { value }\end{array}$} & \multirow{2}{*}{$\begin{array}{l}\text { KMO } \\
\text { value }\end{array}$} & \multicolumn{3}{|c|}{ Bartlett's test of sphericity } & \multirow{2}{*}{$\begin{array}{l}\text { Explained } \\
\text { variance }\end{array}$} & & \\
\hline & & & $\chi^{2}$-value & df & Sig. & & $\begin{array}{l}\text { No. of } \\
\text { items }\end{array}$ & $\begin{array}{c}\text { Cronbach's } \alpha \\
\text { value }\end{array}$ \\
\hline SI & 0.829 & 0.827 & 179.007 & 15 & 0.000 & $51.871 \%$ & 6 & 0.811 \\
\hline II & 0.840 & 0.843 & 303.009 & 15 & 0.000 & $63.137 \%$ & 6 & 0.877 \\
\hline CI & 0.803 & 0.864 & 357.199 & 15 & 0.000 & $66.831 \%$ & 6 & 0.898 \\
\hline SCI & - & 0.693 & 75.083 & 3 & 0.000 & $67.892 \%$ & 3 & 0.760 \\
\hline ECR & 0.899 & 0.767 & 216.344 & 15 & 0.000 & $53.188 \%$ & 6 & 0.811 \\
\hline SOR & 0.818 & 0.889 & 332.572 & 15 & 0.000 & $65.432 \%$ & 6 & 0.894 \\
\hline ENR & 0.870 & 0.826 & 249.035 & 15 & 0.000 & $57.902 \%$ & 6 & 0.847 \\
\hline SD & - & 0.695 & 117.267 & 3 & 0.000 & $74.432 \%$ & 3 & 0.841 \\
\hline
\end{tabular}

Notes: $t$-tabulated $=1.960, n=102$

\section{Results}

A detailed statistical analysis was carried out using the SPSS software. The analysis comprises descriptive statistics, bivariate Pearson correlation, and simple and multiple linear regression.

\subsection{Descriptive statistics}

This section describes both independent and dependent variables from a statistical point of view by finding the mean $(\bar{x})$, standard deviation $(S), t$-value, implementation level, and ranking for each variable. Based on the mean scores, the implementation level of each variable is categorized into three levels: low implementation (if the mean lies between 1 - 2.33), medium implementation (if the mean lies between 2.34 - 3.67), and high implementation 
(if the mean lies between 3.68 - 5). Table 4 shows that the implementation level of the overall SCI is medium $(\bar{x}$ $=3.627, t=42.521, p<0.05)$, while the overall SD is highly implemented by JPFM companies $(\bar{x}=3.755, t=$ $54.974, p<0.05)$. Table 4 also shows that there is a medium to high implementation of SCI sub-variables (SI, II, and CI) of JPFM companies, where CI was rated the highest $(\bar{x}=3.843$, high implementation level), followed by SI $(\bar{x}=3.533$, medium implementation level), and finally II $(\bar{x}=3.507$, medium implementation level). On the other hand, there is also a medium to high implementation of SD sub-variables (ECR, SOR, and ENR) of JPFM companies, where SOR was rated the highest $(\bar{x}=4.018$, high implementation level), followed by ECR $(\bar{x}=3.848$, high implementation level), and finally $\operatorname{ENR}(\bar{x}=3.397$, medium implementation level).

Table 4: Descriptive statistics

\begin{tabular}{ccccccc}
\hline $\begin{array}{c}\text { Variable / Sub- } \\
\text { variable }\end{array}$ & $\bar{x}$ & $S$ & $t$-value & Sig. & Implementation level & Rank \\
\hline SI & 3.533 & 0.629 & 56.764 & 0.000 & Medium & 2 \\
II & 3.507 & 0.772 & 45.888 & 0.000 & Medium & 3 \\
CI & 3.843 & 0.652 & 59.570 & 0.000 & High & 1 \\
SCI & 3.627 & 0.564 & 42.521 & 0.000 & Medium & - \\
ECR & 3.848 & 0.634 & 42.758 & 0.000 & High & 2 \\
SOR & 4.018 & 0.949 & 64.899 & 0.000 & High & 1 \\
ENR & 3.397 & 0.807 & 61.281 & 0.000 & Medium & 3 \\
SD & 3.755 & 0.690 & 54.974 & 0.000 & High & - \\
\hline
\end{tabular}

Notes: $t$-tabulated $=1.980, n=102$

\subsection{Relationships between variables}

To examine the relationships between the variables and sub-variables of the research model, correlation analysis was conducted between the mean of answers for each questionnaire item. Table 5 shows the bivariate Pearson's correlation matrix for all of these variables and sub-variables. The relationships between SCI sub-variables are medium, where the coefficient of correlation $(r)$ values are ranging between 0.487 and 0.557 , while the relationships between SD sub-variables are medium to strong since $r$ values are ranging between 0.535 and 0.706 . On the other hand, the relationships between the overall SCI variable and its sub-variables are very strong due to the high values of $r$ that range between 0.798 and 0.859 . Likewise, the relationships between the overall SD variable and its sub-variables are also very strong due to the high values of $r$ that range between 0.831 and 0.911 .

Table 5: Bivariate Pearson's correlation test

\begin{tabular}{ccccccccc}
\hline & SI & II & CI & SCI & ECR & SOR & ENR & SD \\
\hline SI & 1 & & & & & & \\
II & $0.557^{* *}$ & 1 & & & & & \\
CI & $0.487^{* *}$ & $0.510^{* *}$ & 1 & & & & \\
SCI & $0.813^{* *}$ & $0.859^{* *}$ & $0.798^{* *}$ & 1 & & & \\
ECR & $0.551^{* *}$ & $0.577^{* *}$ & $0.522^{* *}$ & $0.669^{* *}$ & 1 & & \\
SOR & $0.530^{* *}$ & $0.670^{* *}$ & $0.487^{* *}$ & $0.689^{* *}$ & $0.706^{* *}$ & 1 & & \\
ENR & $0.409^{* *}$ & $0.708^{* *}$ & $0.383^{* *}$ & $0.622^{* *}$ & $0.535^{* *}$ & $0.604^{* *}$ & 1 & \\
SD & $0.571^{* *}$ & $0.761^{* *}$ & $0.533^{* *}$ & $0.764^{* *}$ & $0.839^{* *}$ & $0.911^{* *}$ & $0.831^{* *}$ & 1 \\
\hline Notes: ${ }^{* *}$ Correlation is significant at the 0.01 level (two-tailed), $n=102$ & &
\end{tabular}

By looking at $r$ values between each SCI sub-variable and the overall SD, we can conclude that the relationships between them are medium to strong, where II has the highest effect on the overall SD $(r=0.761)$, followed by SI ( $r=0.571)$, then CI $(r=0.533)$. According to Table 5, The correlation between the overall SCI and the overall $\mathrm{SD}$ is rated to be high with $r=0.761$. It is also shown that the overall SCI has an almost equal impact on ECR, SOR, and ENR, where $r$ values are $0.669,0.689$, and 0.622 respectively. Table 5 also shows that II is superior to 
external integration (i.e., SI and CI) in enhancing the ECR $(r=0.577)$, SOR $(r=0.670)$, and ENR $(r=0.708)$. By looking at the effect of external integration on each SD dimension, SI is superior to CI in enhancing the ECR ( $r=$ $0.551)$, SOR $(r=0.530)$, and ENR $(r=0.409)$. It is also worth mentioning that all of these correlations are significant at the 0.01 level of significance.

\subsection{Hypotheses testing}

Multiple regression was used to test the hypotheses of this study. Table 6 shows the regression statistics between the overall SCI (independent variable) and the overall SD (dependent variable). The $r$ value is 0.791 , which means that there is a strong and positive relationship between the SCI and SD variables. Moreover, the coefficient of determination $\left(R^{2}\right)$ is 0.625 , which means that $62.5 \%$ of the variability in the SD variable is explained by the SCI variable. Additionally, the regression statistics $(F=54.539, p<0.05)$ indicates that $H_{1}$ is supported. Therefore, the overall SCI has an effect on the overall SD at the 0.05 level of significance.

Table 6: Regression statistics of SCI against SD $(n=102)$

\begin{tabular}{ccccc}
\hline$r$ & $R^{2}$ & Adjusted $R^{2}$ & $F$-value & Sig. \\
\hline 0.791 & 0.625 & 0.614 & 54.539 & 0.000 \\
\hline
\end{tabular}

Table 7 shows the regression between SCI sub-variables (independent variables) and the overall SD (dependent variable). It is clear from this table that all SI $(t=2.190, p<0.05)$, II $(t=7.479, p<0.05)$, and CI $(t=1.993, p<$ 0.05 ) have a positive and significant effect on SD at the 0.05 level of significance. This indicates that JPFM companies believe that all SCI dimensions can affect SD. A summary of these final hypotheses testing results is presented in Table 8.

Table 7: Regression statistics of SCI sub-variables against SD $(n=102)$

\begin{tabular}{cccccc}
\hline \multirow{2}{*}{ Model } & \multicolumn{2}{c}{$\begin{array}{c}\text { Unstandardized } \\
\text { coefficients }\end{array}$} & $\begin{array}{c}\text { Standardized } \\
\text { coefficients }\end{array}$ & \multirow{2}{*}{$t$-value } & \multirow{2}{*}{ Sig. } \\
\cline { 2 - 4 } & $\mathrm{B}$ & Standard Error & $\beta$-value & & 0.029 \\
\cline { 2 - 4 }$($ Constant $)$ & 0.639 & 0.289 & & 2.210 & 0.031 \\
SI & 0.187 & 0.085 & 0.170 & 2.190 & 0.000 \\
II & 0.527 & 0.070 & 0.590 & 7.479 & 0.049 \\
CI & 0.158 & 0.079 & 0.149 & 1.993 & \\
\hline
\end{tabular}

Table 8: Summary of the hypotheses testing results

\begin{tabular}{cccc}
\hline Hypothesis & Relationship & Support of hypothesis & Implication \\
\hline$H_{1}$ & $\mathrm{SCI} \rightarrow \mathrm{SD}$ & Supported & SCI affects SD \\
$H_{1 \mathrm{a}}$ & $\mathrm{SI} \rightarrow \mathrm{SD}$ & Supported & SI affects SD \\
$H_{\mathrm{lb}}$ & $\mathrm{II} \rightarrow \mathrm{SD}$ & Supported & II affects SD \\
$H_{\mathrm{lc}}$ & $\mathrm{CI} \rightarrow \mathrm{SD}$ & Supported & CI affects SD \\
\hline
\end{tabular}

\section{Discussions}

The results showed that there is a medium to high implementation of SCI sub-variables (SI, II, and CI) of JPFM companies, where CI was rated the highest, followed by SI, and finally II. Likewise, there is a medium to high implementation of SD sub-variables (ECR, SOR, and ENR) of JPFM companies, where SOR was rated the highest, followed by ECR, and finally ENR. It seems that JPFM companies are aware of the importance of implementing SCI elements and their effect on SD. This result is matching with the results of many previous studies that revealed a good implementation of both SCI elements (Ayoub et al., 2017; Bwaliez and Abushaikha, 2019) and SD dimensions (Al Qeed, 2015; Di Bella and Al-Fayoumi, 2016; Obeidat, 2016; Masa'deh et al., 2018; Sharabati, 2018) in the Jordanian context. 
The results also showed that the relationships among SCI sub-variables are medium and significant. However, the relationships among SD sub-variables are medium to strong and significant. Any improvement in one sub-variable of SCI or SD will affect the other sub-variables. This result goes in line with the findings of a recent study conducted by Kang et al. (2018) who found strong inter-construct correlations between all SCI and SD dimensions. Koufteros et al. (2010) and Huo (2012) both showed that II improves both SI and CI. On contrary, Flynn et al. (2010) showed that the manufacturer's efforts in SI and CI help it take full advantage of its II in order to achieve better operational performance. However, Huo (2012) proofed that SI does not affect CI and vice versa. Although less attention has been paid by scholars to the linkages between SD dimensions (Lehtonen, 2004), some scholars have supported the notion that a company's SOR activities concentrating on health and safety programs improves the brand image, which leads to enhanced ECR (Pagell and Gobeli, 2009). Likewise, supporting SOR in terms of employee well-being is positively improving the ENR and the overall SD performance outcomes (Rothenberg et al., 2001). Additionally, SOR and ENR activities can provide long-term economic benefits and a competitive advantage for the company, which leads to improving its ECR (Carter and Rogers, 2008).

Moreover, the relationship between the overall SCI and the overall SD is strong and significant. This indicates that any improvement in the overall SCI will affect the overall SD. This agrees with the scholarly work of Pagell and Wu (2009) who exemplified how SCI leads to ECR, SOR, and ENR using case studies of ten exemplars. This finding is also consistent with Chang et al. (2016) who found that each SCI sub-variable improves SD, and it agrees with Shee et al. (2018) who showed that cloud-enabled SCI is positively related to supply chain performance, which eventually influenced the company's sustainability. On the other hand, this finding is inconsistent with Vickery et al. (2003) who found that there is no significant relationship between SCI and ECR. The finding is also inconsistent with Rosenzweig et al. (2003) who revealed that SCI does not affect ECR in terms of sales growth and customer satisfaction.

The results showed that II has the highest impact on SD. This finding is in line with previous research that proposed the importance of II to improve SD. For example, Flynn et al. (2010) found that II directly and significantly affects both operational and business performance of manufacturing companies. In addition, Huo (2012) showed that II leads to improved ECR of the company. This is also consistent with some previous empirical studies. For instance, Flynn et al. (2010) found that external integration does not affect both operational and business performance. Likewise, Swink et al. (2007) revealed that neither CI nor SI has an impact on the competitive capability of the plant. Huo (2012) found that there is no significant relationship between either SI and ECR or CI and ECR. Additionally, Prajogo et al. (2012) found that neither supplier assessment nor a strategic long-term relationship with supplier affects operational performance of the company in terms of delivery, cost, and quality. Furthermore, Danese and Romano (2011) revealed that CI does not affect the efficiency of manufacturing plants.

The result concerning the significant effect of external integration on SD is consistent with the scholarly work of Kang et al. (2018) who found that SI and CI are vital enablers for both intra- and inter-organizational sustainability management practices that are positively related to the three aspects of sustainability performance. Neutzling $e t$ al. (2018) also asserted the crucial role of inter-organizational relationship integration in achieving ECR, SOR, and ENR, which can be converted into improved SD. In addition, this result goes in line with the absorptive capacity theory (Cohen and Levinthal, 1990), which asserts the vital advantages of a company's ability to identify, assimilate, transform, and apply worthy external knowledge. Furthermore, Allred et al. (2011) found that not only internal but also external integration directly and significantly influences productivity and customer satisfaction, which will be converted into enhanced ECR. Moreover, Stevens and Johnson (2016) mentioned that II lately transitioned to external integration, as there is a limited amount of performance improvement that could be achieved without involving suppliers and customers. This remark agrees with what was revealed in this study.

\section{Conclusions}

\subsection{Theoretical implications}

This study was carried out to investigate the effect of SCI on the SD of JPFM companies. It incorporates SCI into the sustainability literature, providing a new perspective on sustainability and SCM research. Data were collected through a questionnaire from 102 managers of three JPFM companies (JIFCO in Al-Shidiya, JPMC in Aqaba, and 
IJC in Amman). After confirming normality, linearity, multicollinearity, independence of errors, and validity and reliability of the questionnaire items, descriptive statistical analysis, correlation between variables, and multiple linear regression were carried out. The results revealed that both SCI and SD sub-variables were implemented by JPFM companies with different rates. For the SCI sub-variables, CI was rated the highest, followed by SI, and finally II. While for the SD sub-variables, SOR was rated the highest, followed by ECR, and finally ENR. The results also showed that there are positive and significant relationships among SCI sub-variables on one side and among SD sub-variables on the other side. There are also positive and significant relationships between each SCI sub-variable and the overall SD. In general, there is a positive and significant relationship between the overall SCI and the overall SD. However, the results provided evidence that II is superior to external integration (SI and CI) in enhancing SD. In other words, a high significant effect of II on SD was obtained, while lower significant effects of both SI and CI on the overall SD were found.

\subsection{Practical implications}

This study promotes the idea of implementing SCI in phosphate fertilizers manufacturing companies in Jordan in order to enhance their SD. It also recommends these companies rethink their efforts toward economic, social, and environmental responsibilities.

\section{Limitations, future research, and recommendations}

\subsection{Limitations and future research}

Though the current study attained some important findings and insights related to the effect of SCI on SD, it has limitations that can be addressed in future studies. This study was directed toward JPFM companies in Jordan. However, generalizing the results to other industries and countries is suspicious. Therefore, the study at hand can be extended to cement and potash manufacturing industries, and it can be carried out in other Arab and international settings and contexts in order to increase the validity and generalizability. Since this study is crosssectional, a more stringent test of the relationship between SCI and SD requires a longitudinal study, or field experiment, which could involve gathering data over a longer time span. Then, the association between the variation of both independent and dependent variables could be further investigated. This study investigated the direct relationship between SCI and SD. However, future research is needed to investigate the indirect relationship between them through examining the mediating role of several factors.

\subsection{Recommendations for practitioners}

The results showed that II has the highest impact on SD but it has the lowest implementation level by JPFM companies. This implies that these companies should heavily rely on their internal knowledge, operations, and capabilities in order to facilitate and enhance their SD. On the other hand, JPFM companies are recommended to organize training programs jointly with their suppliers to reinforce the aspects of the communications. They are also recommended to apply a fair salary system and hold training sessions for their employees on a continuous basis, which can increase the employees' efficiency. These practices can lead to improved ECR. Besides that, JPFM companies can participate in SOR by supporting higher education not only for the employees but also for their children, and through providing training centers for local community members. Finally, ENR of these companies can be enhanced by using eco-friendly sources of energy to reduce environmental pollution, recycling the industrial waste of gypsum due to its negative impact on the environment, and providing training sessions for employees regarding environmental issues to teach them how they can maintain the clean environment.

\section{References}

1. Abbasi, M. and Nilsson, F. (2012), "Themes and challenges in making supply chains environmentally sustainable”, Supply Chain Management: An International Journal, Vol. 17 No. 5, pp. 517-530.

2. Agyemang, O.S. and Ansong, A. (2017), "Corporate social responsibility and firm performance of Ghanaian SMEs: mediating role of access to capital and firm reputation", Journal of Global Responsibility, Vol. 8 No. 1 , pp. 47-62. 
3. Alkunsol, W.H., Sharabati, A.A., AlSalhi, N.A., and El-Tamimi, H.S. (2019), "Lean six sigma effect on Jordanian pharmaceutical industry's performance”, International Journal of Lean Six Sigma, Vol. 10 No. 1, pp. 23-43.

4. Allred, C.R., Fawcett, S.E., Wallin, C., and Magnan, G.M. (2011), “A dynamic collaboration capability as a source of competitive advantage”, Decision Sciences, Vol. 42 No. 1, pp. 129-161.

5. Al Qeed, M. (2015), "The relationship between corporate social responsibility toward the employees and hotel performance in Jordan”, International Business Research, Vol. 8 No. 1, pp. 197-202.

6. Al-Tahat, M.D. and Bwaliez, O.M. (2015), "Lean-based workforce management in Jordanian manufacturing firms", International Journal of Lean Enterprise Research, Vol. 1 No. 3, pp. 284-316.

7. Ayoub, H.F., Abdallah, A.B., and Suifan, T.S. (2017), "The effect of supply chain integration on technical innovation in Jordan: the mediating role of knowledge management", Benchmarking: An International Journal, Vol. 24 No. 3, pp. 594-616.

8. Baliga, R., Raut, R.D., and Kamble, S.S. (2019), "Sustainable supply chain management practices and performance: an integrated perspective from a developing economy", Management of Environmental Quality: An International Journal, Vol. 31 No. 5, pp. 1147-1182.

9. Berenson, M.L., Levine, D.M., Szabat, K.A., and Stephan, D.F. (2020), Basic Business Statistics: Concepts and Applications, 14th ed., Pearson Education Ltd., Harlow, UK.

10. Boon-itt, S. (2009), "The effect of internal and external supply chain integration on product quality and innovation: evidence from Thai automotive industry", International Journal of Integrated Supply Management, Vol. 5 No. 2, pp. 97-112.

11. Brömer, J., Brandenburg, M., and Gold, S. (2019), "Transforming chemical supply chains toward sustainability - A practice-based view", Journal of Cleaner Production, Vol. 236. https://doi.org/10.1016/j.jclepro.2019.117701.

12. Bollen, L., Vergauwen, P., and Schnieders, S. (2005), "Linking intellectual capital and intellectual property to company performance", Management Decision, Vol. 43 No. 9, pp. 1161-1185.

13. Bwaliez, O.M. and Abushaikha, I. (2019), "Integrating the SRM and lean paradigms: the constructs and measurements", Theoretical Economics Letters, Vol. 9 No. 7, pp. 2371-2396.

14. Carter, C.R. and Rogers, D.S. (2008), “A framework of sustainable supply chain management: moving toward new theory”, International Journal of Physical Distribution \& Logistics Management, Vol. 38 No. 5, pp. 360-387.

15. Chang, W., Ellinger, A.E., Kim, K., and Franke, G.R. (2016), "Supply chain integration and firm financial performance: a meta-analysis of positional advantage mediation and moderating factors", European Management Journal, Vol. 34 No. 3, pp. 282-295.

16. Cohen, W.M. and Levinthal, D.A. (1990), "Absorptive capacity: a new perspective on learning and innovation", Administrative Science Quarterly, Vol. 35 No. 1, pp. 128-152.

17. Danese, P. and Romano, P. (2011), "Supply chain integration and efficiency performance: a study on the interactions between customer and supplier integration", Supply Chain Management: An International Journal, Vol. 16 No. 4, pp. 220-230.

18. Di Bella and Al-Fayoumi, N. (2016), "Perception of stakeholders on corporate social responsibility of Islamic Banks in Jordan", EuroMed Journal of Business, Vol. 11 No. 1, pp. 30-56.

19. Elkington, J. (1998), "Partnership from cannibals with forks: the triple bottom line of 21 st-century business", Environmental Quality Management, Vol. 8 No. 1, pp. 37-51.

20. Fatma, M., Rahman, Z., and Khan, I. (2015), "Building company reputation and brand equity through CSR: the mediating role of trust", International Journal of Bank Marketing, Vol. 33 No. 6, pp. 840-856.

21. Flynn, B.B., Huo, B., and Zhao, X. (2010), "The impact of supply chain integration on performance: a contingency and configuration approach", Journal of Operations Management, Vol. 28 No. 1, pp. 58-71.

22. Gelhard, C. and von Delft, S. (2016), "The role of organizational capabilities in achieving superior sustainability performance“, Journal of Business Research, Vol. 69 No. 10, pp. 4632-4642.

23. Hair, J.F., Black, W.C., Babin, B.J., and Anderson, R.E. (2010), Multivariate Data Analysis, 7th ed., Prentice Hall, Upper Saddle River, NJ.

24. Hair, J.F., Hult, T.M., Ringle, C.M., and Sarstedt, M. (2014), A Primer on Partial Least Squares Structural Equation Modeling (PLS-SEM), Sage Publications, Inc., Thousand Oaks, CA. 
25. Hajmohammad, S., Vachon, S., Klassen, R.D., and Gavronski, I. (2013), "Lean management and supply management: their role in green practices and performance", Journal of Cleaner Production, Vol. 39, pp. 312-320.

26. Hammouri, H., Kabore, P., and Kinnaert, M. (2009), “Adopting and applying eco-design techniques: a practitioners perspective”, Journal of Cleaner Production, Vol. 17 No. 5, pp. 549-558.

27. Hall, J. and Matos, S. (2010), "Incorporating impoverished communities in sustainable supply chains", International Journal of Physical Distribution \& Logistics Management, Vol. 40 Nos. 1/2, pp. 124-147.

28. Harris, J.R., Guffey, H.J., and Laumer, J.F. (1979), "The windshield method of questionnaire distribution: a viable alternative", Journal of the Academy of Marketing Science, Vol. 7 No. 3, pp. 184-191.

29. Huo, B. (2012), "The impact of supply chain integration on company performance: an organizational capability perspective", Supply Chain Management: An International Journal, Vol. 17 No. 6, pp. 596-610.

30. Huq, F.A., Chowdhury, I.N., and Klassen, R.D. (2016), "Social management capabilities of multinational buying firms and their emerging market suppliers: an exploratory study of the clothing industry", Journal of Operations Management, Vol. 46, pp. 19-37.

31. Kaiser, H. (1974), “An index of factor simplicity”, Psychometrika, Vol. 39, pp. 31-36.

32. Kang, M., Yang, M.G., Park, Y., and Huo, B. (2018), "Supply chain integration and its impact on sustainability”, Industrial Management \& Data Systems, Vol. 118 No. 9, pp. 1749-1765.

33. Kim, D.Y. (2013), "Relationship between supply chain integration and performance", Operations Management Research, Vol. 6 No. 1, pp. 74-90.

34. Klassen, R.D. (2001), "Plant-level environmental management orientation: the influence of management views and plant characteristics", Production and Operations Management, Vol. 10 No. 3, pp. 257-275.

35. Koufteros, X.A., Rawski, G.E., and Rupak, R. (2010), “Organizational integration for product development: the effects on glitches, on-time execution of engineering change orders, and market success", Decision Sciences, Vol. 41 No. 1, pp. 49-80.

36. Krajewski, L.J., Malhotra, M.K., and Ritzman, L.P. (2019), Operations Management: Processes and Supply Chains, 12th ed., Pearson Education Ltd., Essex, England.

37. Lau, A., Yam, R., and Tang, E. (2010), "Supply chain integration and product modularity: an empirical study of product performance for selected Hong Kong manufacturing industries", International Journal of Operations and Production Management, Vol. 30 No. 1, pp. 20-56.

38. Lehtonen, M. (2004), "The environmental - social interface of sustainable development: capabilities, social capital, institutions", Ecological Economics, Vol. 49 No. 2, pp. 199-214.

39. Li, S., Ragu-Nathan, B., Ragu-Nathan, T.S., and Subba Rao, S. (2006), "The impact of supply chain management practices on competitive advantage and organizational performance”, Omega, Vol. 34 No. 2 , pp. 107-124.

40. Lii, P. and Kuo, F.I. (2016), "Innovation-oriented supply chain integration for combined competitiveness and firm performance", International Journal of Production Economics, Vol. 174 No. 1, pp. 142-155.

41. Litwin, M.S. (1995), How to Measure Survey Reliability and Validity, Sage Publications Inc., Thousand Oaks, CA.

42. Mackelprang, A.W., Robinson, J.L., Bernardes, E., and Webb, G.S. (2014), "The relationship between strategic supply chain integration and performance: a meta-analytic evaluation and implications for supply chain management research", Journal of Business Logistics, Vol. 35 No. 1, pp. 71-96.

43. Masa'deh, R., Alrowwad, A., Alkhalafat, F., Obeidat, B., and Abualoush, S. (2018), "The role of corporate social responsibility in enhancing firm performance from the perspective of IT employees in Jordanian Banking sector: the mediating effect of transformational leadership", Modern Applied Science, Vol. 12 No. 7, pp. 1-26.

44. Narasimhan, R. and Das, A. (2001), "The impact of purchasing integration and practices on manufacturing performance", Journal of Operations Management, Vol. 19 No. 5, pp. 593-609.

45. Neutzling, D.M., Land, A., Seuring, S., and do Nascimento, L.F.M. (2018), "Linking sustainability-oriented innovation to supply chain relationship integration", Journal of Cleaner Production, Vol. 172, pp. 3448-3458.

46. Obeidat, B.Y. (2016), "Exploring the relationship between corporate social responsibility, employee engagement, and organizational performance: the case of Jordanian mobile telecommunication companies", International Journal of Communications, Network and System Sciences, Vol. 9, No. 9, pp. 361-386. 
47. Pagell, M. (2004), "Understanding the factors that enable and inhibit the integration of operations, purchasing, and logistics", Journal of Operations Management, Vol. 22 No. 5, pp. 459-487.

48. Pagell, M. and Gobeli, D. (2009), "How plant managers' experiences and attitudes toward sustainability relate to operational performance", Production \& Operations Management, Vol. 18 No. 3, pp. 278-299.

49. Pagell, M. and $\mathrm{Wu}, \mathrm{Z}$. (2009), "Building a more complete theory of sustainable supply chain management using case studies of 10 exemplars", Journal of Supply Chain Management, Vol. 45 No. 2, pp. 37-56.

50. Prajogo, D., Chowdhury, M., Yeung, A.C.L., and Cheng, T.C.E. (2012), "The relationship between supplier management and firm's operational performance: a multi-dimensional perspective", International Journal of Production Economics, Vol. 136 No. 1, pp. 123-130.

51. Ralston, P.M., Blackhurst, J., Cantor, D.E., and Crum, M.R. (2015), "A structure-conduct-performance perspective of how strategic supply chain integration affects firm performance", Journal of Supply Chain Management. Vol. 51 No. 2, pp. 47-64.

52. Rifai, F.A., Yousif, A.S.H., Bwaliez, O.M., Al-Fawaeer, M.A.R., and Ramadan, B.M. (2021), "Employee's attitude and organizational sustainability performance: an evidence from Jordan's banking sector", Research in World Economy, Vol. 12 No. 2, pp. 166-177.

53. Rothenberg, S., Pil, F.K., and Maxwell, J. (2001), "Lean, green, and the quest for superior environmental performance", Production \& Operations Management, Vol. 10 No. 3, pp. 228-243.

54. Rosenzweig, E.D., Roth, A.V., and Dean, J.W. (2003), "The influence of an integration strategy on competitive capabilities and business performance: an exploratory study of consumer products manufacturers", Journal of Operations Management, Vol. 21 No. 4, pp. 437-456.

55. Sarkis, J., Gonzalez-Torre, P., and Adenso-Diaz, B. (2010), "Stakeholder pressure and the adoption of environmental practices: the mediating effect of training", Journal of Operations Management, Vol. 28 No. 2, pp. 163-176.

56. Sekaran, U. and Bougie, R. (2010), Research Methods for Business: A Skill Building Approach, 5th ed., John Wiley \& Sons Ltd., West Sussex.

57. Sharabati, A.A. (2018), "Effect of corporate social responsibility on Jordan pharmaceutical industry's business performance", Social Responsibility Journal, Vol. 14 No. 3, pp. 566-583.

58. Shee, H., Miah, S.J., Fairfield, L., and Pujawan, N. (2018), "The impact of cloud-enabled process integration on supply chain performance and firm sustainability: the moderating role of top management", Supply Chain Management: An International Journal, Vol. 23 No. 6, pp. 500-517.

59. Shin, J., Kim, C., and Yang, H. (2018), "The effect of sustainability as innovation objectives on innovation efficiency", Sustainability, Vol. 10 No. 6. https://doi.org/10.3390/su10061966

60. Stevens, G.C. and Johnson, M. (2016), "Integrating the supply chain... 25 years on", International Journal of Physical Distribution \& Logistics Management, Vol 46 No. 1, pp. 19-42.

61. Swink, M., Narasimhan, R., and Wang, C. (2007), "Managing beyond the factory walls: effects of four types of strategic integration on manufacturing plant performance", Journal of Operations Management, Vol. 25 No. 1, pp. 148-164.

62. Ta'Amnha, M., Samawi, G.A., Bwaliez, O.M., and Magableh, I.K. (2021), "COVID-19 organizational support and employee voice: insights of pharmaceutical stakeholders in Jordan", Corporate Ownership \& Control, Vol. 18 No. 3, pp. 367-378.

63. Titi, A., Al Rawashdeh, R., and Al Tarawneh K. (2019), "Peak phosphate in Jordan”, International Journal of Mining and Mineral Engineering, Vol. 10 No. 1, pp. 27-50.

64. Vickery, S.K., Jayaram, J., Droge, C., and Colantone, R. (2003), "The effects of an integrative supply chain strategy on customer service and financial performance: an analysis of direct versus indirect relationships", Journal of Operations Management, Vol. 21 No. 5, pp. 523-539.

65. WCED (1987), World Commission on Environment and Development, Our Common Future (the Brundtland report), Oxford University Press, Oxford.

66. Winter, M. and Knemeyer, A.M. (2013), "Exploring the integration of sustainability and supply chain management: current state and opportunities for future inquiry", International Journal of Physical Distribution \& Logistics Management, Vol. 43 No. 1, pp. 18-38.

67. Wolf, J. (2014), "The relationship between sustainable supply chain management, stakeholder pressure, and corporate sustainability performance", Journal of Business Ethics, Vol. 119 No. 3, pp. 317-328. 
68. Worthington, I. (2008), "Researching the drivers of socially responsible purchasing: a cross-national study of supplier diversity initiatives", Journal of Business Ethics, Vol. 79 No. 3, pp. 319-331.

69. Yadav, G., Mangla, S.K., Luthra, S., and Jakhar, S. (2018), "Hybrid BWM-ELECTRE-based decision framework for effective offshore outsourcing adoption: a case study", International Journal of Production Research, Vol. 56 No. 18, pp. 6259-6278.

70. Yang, C.L., Lin, S.P., Chan, Y.H., and Sheu, C. (2010), "Mediated effect of environmental management on manufacturing competitiveness: an empirical study", International Journal of Production Economics, Vol. 123 No. 1, pp. 210-220.

\section{Appendix}

Questionnaire

Kindly indicate the degree of implementation of each of the following practices in your company (Use the rating scale from $1=$ not adopted to $5=$ fully adopted and centered at $3=$ partially adopted).

\section{Supplier integration (SI)}

SI1: Our company maintains a complete profile of the suppliers.

SI2: Our company sends/receives data to/from suppliers via the Internet.

SI3: Our company gains best price offer for the raw materials.

SI4: Our company acquires quality raw materials as needed.

SI5: Our company makes order at suppliers timely.

SI6: Our company receives raw materials just in time.

SI7: Our company shares expertise with the suppliers.

SI8: Our company organizes training programs jointly with its suppliers.

\section{Internal integration (II)}

II1: There is continuous interdepartmental coordination in our company.

II2: Interdepartmental data sharing is performed timely.

II3: In our company, the departments cooperate to resolve conflicts and problems among them, when they arise.

II4: In our company, department's managers communicate effectively with each other.

II5: In our company, each department has a high level of responsiveness to meet other departments' needs.

II6: Our company encourages boss-employee communications on continuous basis.

II7: Our company schedules the interdepartmental production processes.

II8: Our company uses cross-functional teams in product and process improvement.

\section{Customer integration (CI)}

CI1: Our company has a customer database.

CI2: Our company communicates with customers online.

CI3: Our company delivers orders to customers timely.

CI4: Our company offers quality products in order to satisfy customers.

CI5: Our company offers competitive products in terms of price.

CI6: Our company provides suitable transport means to deliver its shipments to customers safely.

CI7: Our company shows interest in customer complaints and suggestions.

CI8: Our company is motivated by customer satisfaction.

\section{Economic responsibility (ECR)}

ECR1: Our company fulfills all due tax payments.

ECR2: Our company contributes to an increased gross domestic product (GDP) of the Jordanian economy.

ECR3: Our company contributes to reduce unemployment rate through providing training and opportunities.

ECR4: Our company attracts foreign investments to support the national economy.

ECR5: Our company generates foreign currency to the country.

ECR6: Our company adopts best practices in exploiting the natural resources.

ECR7: Our company uses energy-saving strategies and alternate power solutions. 
ECR8: Our company diversifies its products offered in the global market.

\section{Social responsibility (SOR)}

SOR1: Our company provides physical support to the local non-governmental organizations (NGOs).

SOR2: Our company provides health insurance plan to the employees and their families.

SOR3: Our company provides health insurance plan for retired employees and their families.

SOR4: Our company applies a fair system.

SOR5: Our company supports the higher education for employees and their children.

SOR6: Our company provides training centers for local community members.

SOR7: Our company cooperates with the universities for scientific research purposes.

SOR8: Our company applies public safety measures for the employees.

\section{Environmental responsibility (ENR)}

ENR1: Our company recycles its industrial waste of gypsum.

ENR2: Our company uses modern technology to reduce poisonous emissions.

ENR3: Our company uses eco-friendly sources of energy.

ENR4: Our company installed waste water treatment plant to protect against the pollution of groundwater.

ENR5: Our company is careful about using environmentally clean trucks.

ENR6: Our company grows trees to increase the vegetation.

ENR7: Our company adheres to domestic and international regulations as to protect the environment.

ENR8: Our company holds training sessions for employees regarding environmental issues.

Received: November 05, 2020

Accepted: December 22, 2020 